\title{
Association of BCSC-1 and MMP-14 with human breast cancer
}

\author{
DALIN DI $^{1}$, LEI CHEN ${ }^{2}$, YINGYING GUO $^{1}$, LINA WANG $^{1}$, HUIDONG WANG $^{3}$ and JIYU JU $^{1}$ \\ ${ }^{1}$ Department of Immunology, Weifang Medical University; ${ }^{2}$ Department of Hematology, The Hospital Affiliated to \\ Weifang Medical University; ${ }^{3}$ Breast Surgery Center, Weifang People's Hospital, Weifang, Shandong 261053, P.R. China
}

Received August 17, 2017; Accepted January 22, 2018

DOI: $10.3892 / \mathrm{ol} .2018 .7972$

\begin{abstract}
Breast cancer suppressor candidate-1 (BCSC-1) is a candidate tumor suppressor gene that was identified recently. Decreased levels of BCSC-1 have been detected in a variety of cancer types in previous studies. Matrix metalloproteinase (MMP)-14 is a membrane-type MMP that plays an important role in tumor progression and prognosis. Previous research has indicated that MMP-14 is highly expressed in different cancer types and promotes tumor invasion or metastasis by remodeling the extracellular matrix. However, there have been few reports on BCSC-1 and MMP-14 in human breast cancer in recent years. In the present study, the association of BCSC-1 and MMP-14 with human breast cancer was investigated. The immunohistochemical analysis results revealed reduced expression of BCSC-1 and overexpression of MMP-14 in breast cancer tissues compared with adjacent normal breast tissues. Quantitative polymerase chain reaction and western blot analyses also showed that BCSC-1 was expressed at significantly lower levels, and that MMP-14 was expressed at significantly higher levels in breast cancer tissues compared with healthy breast tissue. Furthermore, decreased expression of BCSC-1 and overexpression of MMP-14 were associated with tumor cellular differentiation, lymph node metastasis and distant metastasis. A correlational analysis between BCSC-1 and MMP-14 was also conducted, and the results indicated a negative correlation between the two. In conclusion, the current findings indicate that BCSC-1 is downregulated, while MMP-14 is overexpressed in human breast cancer. These two genes may play important roles during the process of human breast cancer development.
\end{abstract}

\section{Introduction}

Due to its increasing rates of incidence and mortality, cancer is the leading cause of death and a major public health

Correspondence to: Dr Jiyu Ju, Department of Immunology, Weifang Medical University, Room 422, Science and Technology Building C, 7166 Baotong Street, Weifang, Shandong 261053, P.R. China

E-mail: jujiyu@wfmc.edu.cn

Key words: BCSC-1, MMP-14, breast cancer, immunohistochemical concern, with $>1.6$ million new diagnoses and 1.2 million cancer-associated deaths occurring each year in China (1). Breast cancer is one of the most common and aggressive malignancies and accounts for $\sim 20 \%$ of cancer-related deaths in women, according to WHO statistics. Breast cancer is also the most prevalent cancer among Chinese women, and its incidence continues to increase by $\sim 5 \%$ each year. Despite tremendous advances in diagnostic and therapeutic methods in recent years, breast cancer remains a complex malignancy in terms of clinical treatment $(2,3)$. The majority of patients with breast cancer tend to be diagnosed in the later stages of disease due to a lack of early specific symptoms or biomarkers. Therefore, improving early diagnosis and targeted therapies is particularly important for breast cancer. Accumulating evidence has confirmed that the invasion or metastasis of breast cancer cells is a major factor that causes breast cancer-related death.

The breast cancer suppressor candidate-1 (BCSC-1) gene is a recently identified tumor suppressor gene that is located at chromosome 11q23 and can encode a 786-amino-acid protein with an $86-\mathrm{kDa}$ molecular weight (4). Previous studies have shown that BCSC-1 expression is relatively low in different types of tumor cells, including nasopharyngeal carcinoma, cervical carcinoma and melanoma cells (5-7). In our previous study, we also detected low expression of BCSC-1 in liver cancer, lung cancer and esophageal squamous cell carcinoma (ESCC) (8). These findings indicate that low expression of BCSC-1 may promote tumorigenesis. However, the relationship between BCSC-1 and human breast cancer remains unclear.

Accumulating evidence has also confirmed that matrix metalloproteinases (MMPs) play an important role in tumor invasion and metastasis. As an important member of the MMP family, MMP-14 was the first membrane-type MMP (MT1-MMP) to be identified. MMP-14 is widely expressed on the surfaces of a large variety of cancer cells, such as gastric, lung or liver cancer cells, and can insert itself into the membrane via a transmembrane domain (9). MMP-14 is also involved in a variety of biological processes, such as basement membrane remodeling, tumor cell proliferation and invasion, angiogenesis and fibrous tissue expansion. In particular, MMP-14 can be produced by tumor cells and does not require additional activation because of its capacity to be presented on the cell surface in an active form. A previous study demonstrated that MMP-14 expression in tumor cells significantly correlated with enhanced cell migration capacity and poor patient prognosis (10-12). 
Recent reports regarding BCSC-1 and MMP-14, and particularly their relationship with one another in human tissues, are rare. In the present study, we investigated BCSC-1 and MMP-14 expression in breast cancer tissues by immunohistochemistry, and then verified this expression at the mRNA and protein levels using reverse transcription-quantitative PCR (RT-qPCR) and western blotting. The associations of these proteins with the clinical and pathological characteristics of breast cancer patients were also evaluated. The aim of the study was to investigate the prognostic value of BCSC-1 and MMP-14 in breast cancer.

\section{Materials and methods}

Tissue microarrays and clinical tissue specimens. A breast cancer tissue microarray consisting of 69 breast cancer cases and 3 normal breast tissues cases was purchased from Alenabio (Xian, China; no. BC08013a). A total of 127 patients with pathologically and clinically confirmed breast cancer, who were treated at the Breast Surgery Center of Weifang People's Hospital (Weifang, China), were included in this study for further verification of the tissue microarray results and other analyses. The present study was approved by the Ethics Committee of Weifang People's Hospital and written informed consent was obtained from all patients. The breast cancer tissues and paired adjacent normal breast tissues were obtained before patients received any other treatments. All samples were stored at $-80^{\circ} \mathrm{C}$ prior to use for RNA isolation or protein extraction. Tissue samples collected from the breast cancer patients were fixed in formalin and embedded in paraffin. Approximately $5-\mu \mathrm{m}$-thick, paraffin-embedded sections were deparaffinized in xylene and rehydrated in graded ethanol. The tissue microarray and clinical tissue specimens were placed in EDTA buffer at $100^{\circ} \mathrm{C}$ for $20 \mathrm{~min}$ for antigen retrieval, and then incubated at $4^{\circ} \mathrm{C}$ overnight with mouse anti-human BCSC-1 antibody (cat. no. ab64977; 1:500; Abcam, Cambridge, MA, USA) and mouse anti-human MMP-14 antibody (cat. no. ab51074; 1:500; Abcam). The peroxidase-conjugated anti-mouse secondary antibody (cat. no. SP-0022; ZSGB-BIO, Beijing, China) was then added at a 1:1,000 dilution, followed by the addition of DAB substrate, according to the manufacturer's instructions. The degree of immunostaining was then observed and scored. The staining was graded as follows: 0 , absent; 1 , weak; 2 , moderate; and 3 , strong. The percentage of positively stained cells was graded as follows: 0 , no staining; $1,0-25 \% ; 2,26-50 \% ; 3,51-75 \%$; and $4,76-100 \%$. The final score was calculated by multiplying the staining intensity and the percentage of positive cells, and total final scores were classified as follows: A score of $\leq 2$ was negative (-); 3-4 was weak (+); 6-8 was moderate $(++)$ and 9-12 was strong $(+++)$. Scores of $(-)$ and $(+)$ were regarded as low expression, while $(++)$ and $(+++)$ were regarded as high expression.

RNA extraction and RT-qPCR. Total RNA from the frozen tissue specimens was extracted using TRIzol reagent (cat. no. 9108), and cDNA was synthesized from $0.5 \mu \mathrm{g}$ of RNA using RT reagents (cat. no. DRR036s; both Takara, Dalian, China). qPCR was performed according to the manufacturer's protocol. SYBR Premix Ex Taq ${ }^{\mathrm{TM}}$ (cat. no. DRR820s; Takara) was used for qPCR in a LightCycler 480 instrument (Roche, Basel, Switzerland). The PCR conditions were as follows: Initial denaturation at $95^{\circ} \mathrm{C}$ for $30 \mathrm{sec}$; followed by 35 cycles of denaturation at $94^{\circ} \mathrm{C}$ for $30 \mathrm{sec}$, annealing at $50^{\circ} \mathrm{C}$ for $30 \mathrm{sec}$, and extension at $70^{\circ} \mathrm{C}$ for $30 \mathrm{sec}$. The relative mRNA expression level was determined by normalizing the cycle threshold $(\mathrm{Cq})$ of the gene of interest to that of $\beta$-actin using the $2^{-\Delta \Delta C t}$ formula. The following specific primer pairs were used in the present study: BCSC-1 forward, 5'-TGCTTCTGCCCCATTGAAGA-3' and reverse, 5'-CTGTGCTGGTCCTTGTGAC-3'; MMP-14 forward, 5'-CGAGGTGCCCTATGCCTAC-3' and reverse, 5'-CTCGGCAGAGTCAAAGTGG-3'; $\beta$-actin forward, 5'-CCTAGAAGCATTTGCGGTGG-3' and reverse, 5'-GAGCTACGAGCTGCCTGACG-3'

Western blot analysis. The breast cancer samples were prepared by homogenizing frozen tissues, and proteins were extracted using cell lysis buffer (Beyotime Biotechnology, Haimen, China) containing protease inhibitors. The mixture was incubated on ice for $30 \mathrm{~min}$ and cell debris was removed by centrifugation at $12,000 \mathrm{x} \mathrm{g}$ for $5 \mathrm{~min}$. The protein concentrations were measured using BCA kits (Pierce Biotechnology, Inc., Rockford, IL, USA). Subsequently, $40 \mu \mathrm{g}$ of protein per lane was separated by SDS-PAGE and subsequently transferred onto nitrocellulose membranes (Millipore, Bedford, MA, USA). The proteins were blocked and incubated with goat anti-human BCSC-1 (cat. no. sc-137568; 1:1,000; Santa Cruz Biotechnology, Santa Cruz, CA, USA), mouse anti-human MMP-14 (cat. no. ab51074; 1:1,000 dilution; Abcam) and mouse anti-human $\beta$-actin (cat. no. AA128; 1:1,000 dilution; Beyotime Biotechnology) antibodies overnight at $4^{\circ} \mathrm{C}$. After washing with TBST buffer, the blots were incubated with the corresponding horseradish peroxidase-conjugated secondary antibodies (cat. nos. A0181 and A0216; 1:1,000 dilution; Beyotime Biotechnology) and visualized using ECL detection reagent (Sangon Biotech, Shanghai, China).

Statistical analysis. All data were analyzed using SPSS 10.0 software (SPSS, Inc., Chicago, IL, USA). $\chi^{2}$ and Fisher's exact tests were used to analyze the associations between BCSC-1 and MMP-14 expression and the clinicopathological characteristics of the patients. Spearman's rank correlation was used to analyze the correlation between BCSC-1 and MMP-14 expression levels. $\mathrm{P}<0.05$ was considered to indicate a statistically significant difference.

\section{Results}

Expression of BCSC-1 and MMP-14 in breast cancer tissue microarrays and clinical tissue specimens. To investigate the function of BCSC-1 and MMP-14in breast cancer, we evaluated their expression in a breast cancer tissue microarray using immunohistochemistry firstly. For BCSC-1, 42 breast cancer tissues exhibited low expression and 27 breast cancer tissues exhibited high expression, while all 3 normal tissue samples exhibited high expression (Fig. 1). For MMP-14, 12 breast cancer tissues exhibited low expression and 57 breast cancer tissues exhibited high expression, while 2 of the normal tissue samples exhibited low expression and 1 exhibited high 
A
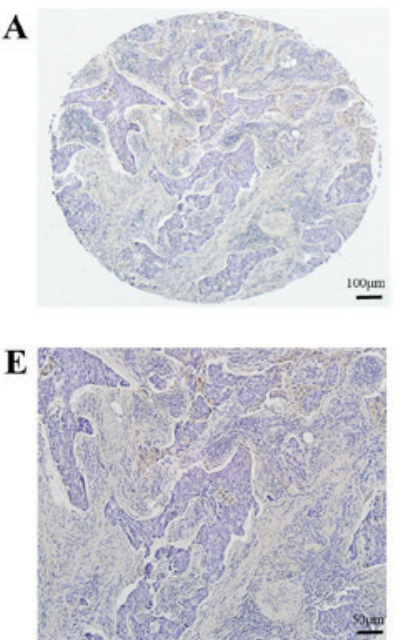

Negative (-)
B
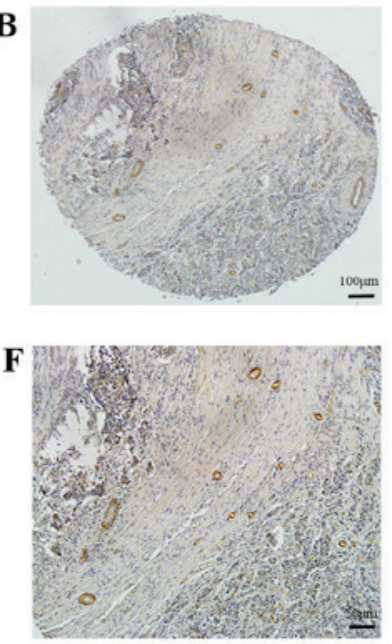

Weak (+)
C
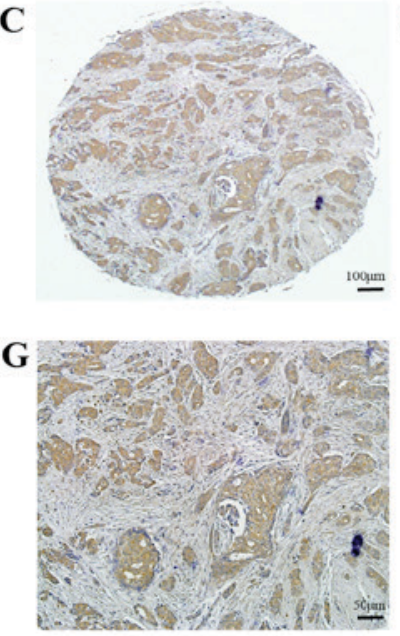

Moderate (++)
D
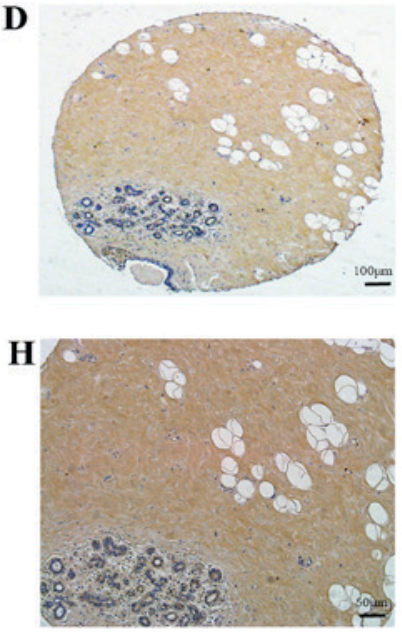

Strong $(+++)$

Figure 1. Immunohistochemical staining of BCSC-1 in tissue microarrays. Tissue microarrays were immunohistochemically stained using an antibody against human BCSC-1. (A and E) Breast cancer tissues exhibiting negative expression (-); (B and F) breast cancer tissues exhibiting weak expression (+); (C and $\mathrm{G})$ breast cancer tissues exhibiting moderate expression (++); (D and H) normal breast tissues exhibiting strong expression (+++). Representative images are shown. BCSC-1, breast cancer suppressor candidate-1.

A

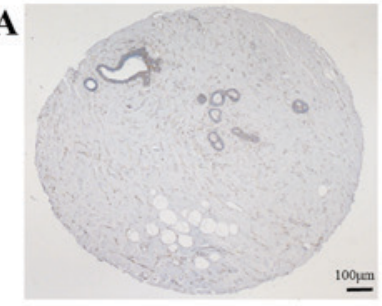

$\mathbf{E}$

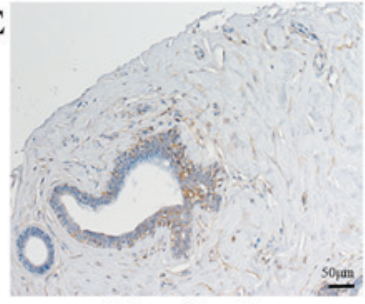

Negative (-)
B

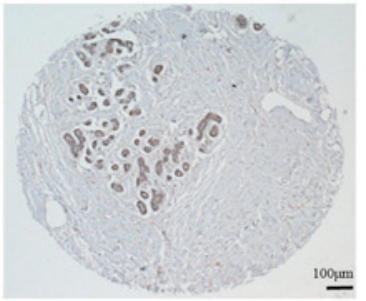

F

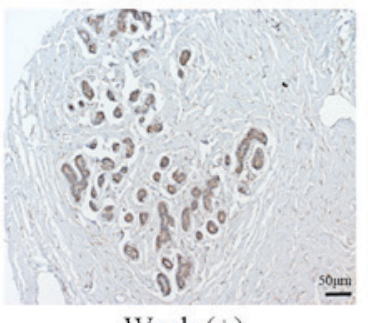

C

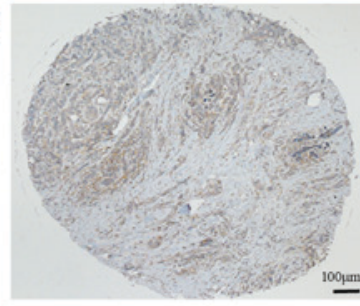

G

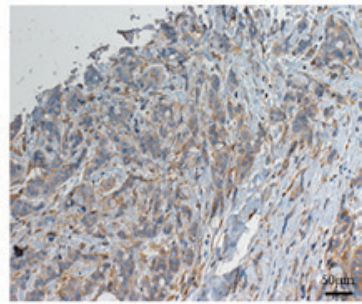

Moderate (++)

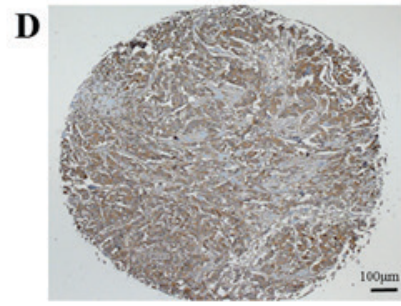

H

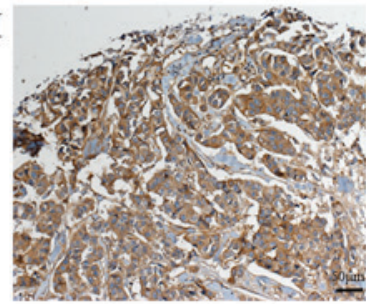

Strong $(+++)$

Figure 2. Immunohistochemical staining of MMP-14 in tissue microarrays. Tissue microarrays were immunohistochemically stained using an antibody against human MMP-14. (A and E) Normal breast tissues exhibiting negative expression (-); (B and F) breast cancer tissues exhibiting weak expression (+); (C and $\mathrm{G}$ ) breast cancer tissues exhibiting moderate expression (++); (D and H) breast cancer tissues exhibiting strong expression (+++). Representative images are shown. MMP, matrix metalloproteinase.

expression (Fig. 2). For further confirmation, we collected 127 pathologically and clinically confirmed breast cancer specimens from patients treated at the Breast Surgery Center of Weifang People's Hospital, for BCSC-1, 82 breast cancer tissues exhibited low expression and 45 breast cancer tissues exhibited high expression, whereas 40 adjacent normal breast tissues exhibited low expression and 87 normal breast tissues exhibited high expression (Fig. 3). For MMP-14,56 breast cancer tissues exhibited low expression and 71 breast cancer tissues exhibited high expression, whereas 92 adjacent normal breast tissues exhibited low expression and 35 adjacent normal breast tissues exhibited high expression (Fig. 4). The results of clinical tissue specimens were in accordance with those obtained from the tissue microarrays. In general, for BCSC-1, 124 (63.27\%) breast cancer tissues exhibited low expression and $72(36.73 \%)$ breast cancer tissues exhibited high expression, whereas 40 (30.77\%) adjacent normal breast tissues exhibited low expression and 90 (69.23\%) normal breast tissues exhibited high expression. For MMP-14, 68 (34.69\%) breast cancer tissues exhibited low expression and $128(65.31 \%)$ breast cancer tissues exhibited high expression, whereas 94 (72.31\%) adjacent normal breast tissues exhibited low expression and 36 (27.69\%) adjacent normal breast tissues exhibited high expression, the expression level of BCSC-1 and MMP-14 differed significantly between breast cancer and normal breast tissues, the expression level of BCSC-1 in breast cancer was significantly lower than of normal breast tissues, the expression level of MMP-14 in breast cancer was significantly higher than in the normal breast tissues $(\mathrm{P}<0.05)$. These results suggest that $\mathrm{BCSC}-1$ 
A

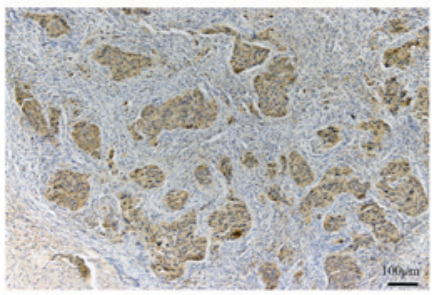

$\mathrm{C}$

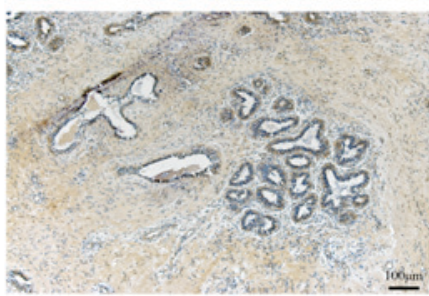

$\mathrm{E}$

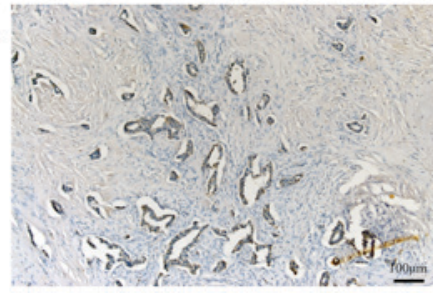

$\mathrm{B}$
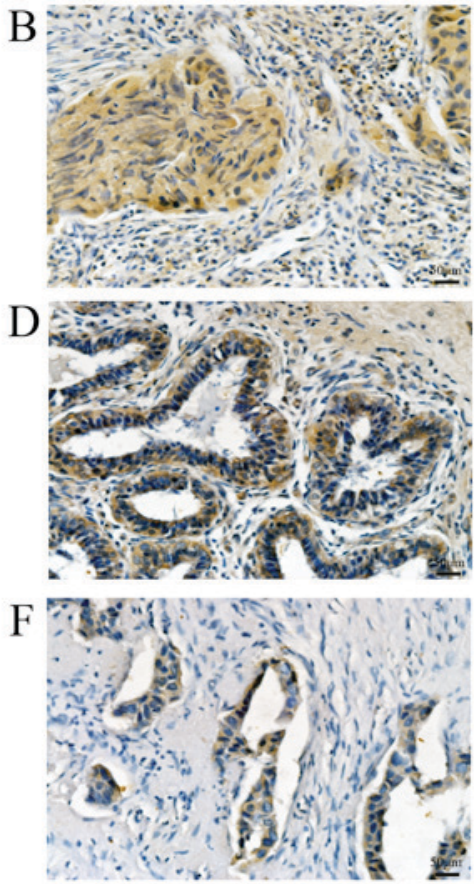

Figure 3. Expression of BCSC-1 in breast cancer tissues with different degrees of differentiation. (A and B) Strong staining of BCSC-1 in breast cancer with good differentiation; (C and D) moderate BCSC-1 expression in breast cancer with moderate differentiation; (E and F) weak staining of BCSC-1 in breast cancer with poor differentiation. Magnification, x100 (left); x400 (right). Representative images are shown. BCSC-1, breast cancer suppressor candidate-1.
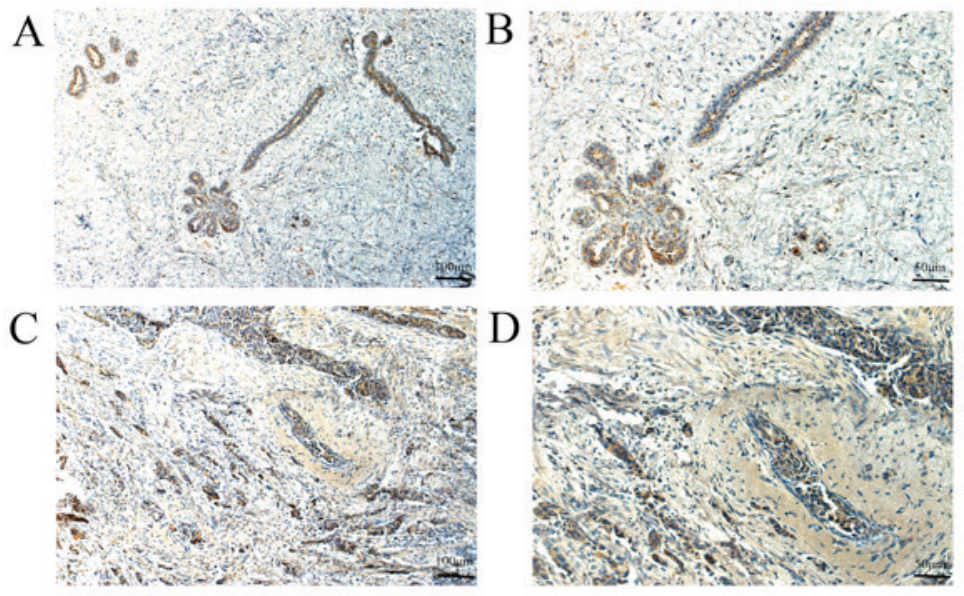

$\mathrm{E}$
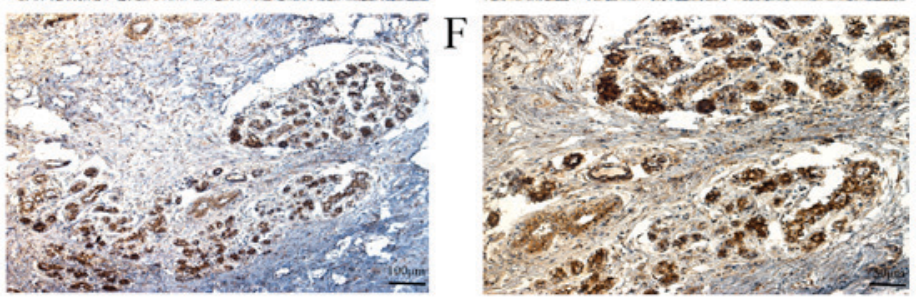

Figure 4. Expression of MMP-14 in breast cancer tissues with different degrees of differentiation. (A and B) Weak staining of MMP-14 in breast cancer with good differentiation; (C and D) moderate MMP-14 expression in breast cancer with moderate differentiation; (E and F) strong staining of MMP-14 in breast cancer with poor differentiation. Magnification, x100 (left); x400 (right). Representative images are shown. MMP, matrix metalloproteinase.

and MMP-14 may be involved in the pathogenesis of breast cancer (Table I).

Association of BCSC-1 and MMP-14 expression with the clinicopathological features of breast cancer patients. The associations between BCSC-1 and MMP-14 expression (low expression or high expression) and the clinicopathological features of breast cancer were evaluated in the present study. The results indicated that neither BCSC-1 or MMP-14 expression status was associated significantly with patient age, histological type or clinical stage $(\mathrm{P}>0.05)$, but that both were closely associated with tumor differentiation, lymph node metastasis and distant metastasis $(\mathrm{P}<0.05)$, implying that $\mathrm{BCSC}-1$ and MMP-14 may participate in breast cancer metastasis (Table II). 
Table I. Expression of BCSC-1 and MMP-14 in breast cancer tissues compared with normal breast tissues.

\begin{tabular}{|c|c|c|c|c|c|c|c|}
\hline \multirow[b]{2}{*}{ Sample } & \multirow[b]{2}{*}{ No. } & \multicolumn{2}{|c|}{ BCSC-1 } & \multirow[b]{2}{*}{ P-value } & \multicolumn{2}{|c|}{ MMP-14 } & \multirow[b]{2}{*}{ P-value } \\
\hline & & Low $(\%)$ & High (\%) & & Low (\%) & High (\%) & \\
\hline Breast cancer & 196 & $124(63.27)$ & $72(36.73)$ & $<0.01^{\mathrm{a}}$ & $68(34.69)$ & $128(65.31)$ & $<0.01^{\mathrm{a}}$ \\
\hline Adjacent normal tissues & 130 & $40(30.77)$ & $90(69.23)$ & & $94(72.31)$ & $36(27.69)$ & \\
\hline
\end{tabular}

${ }^{a} \mathrm{P}<0.05$ was considered to indicate statistical significance. BCSC-1, breast cancer suppressor candidate-1; MMP, matrix metalloproteinase.

Table II. Association of BCSC-1 and MMP-14 expression with the clinicopathological features of breast cancer patients.

\begin{tabular}{|c|c|c|c|c|c|c|c|}
\hline \multirow[b]{2}{*}{ Clinical feature } & \multirow[b]{2}{*}{ No. } & \multicolumn{2}{|c|}{ BCSC-1 expression } & \multirow[b]{2}{*}{ P-value } & \multicolumn{2}{|c|}{ MMP-14 expression } & \multirow[b]{2}{*}{ P-value } \\
\hline & & Low $(\%)$ & High (\%) & & Low $(\%)$ & High $(\%)$ & \\
\hline Age, years & & & & 0.085 & & & 0.111 \\
\hline$<35$ & 132 & 78 (59.09) & $54(40.91)$ & & $51(38.64)$ & $81(61.36)$ & \\
\hline$\geq 35$ & 64 & $46(71.88)$ & $18(28.12)$ & & $17(26.56)$ & $47(73.44)$ & \\
\hline Histological type & & & & 0.395 & & & 0.130 \\
\hline Invasive ductal carcinoma & 169 & $109(64.50)$ & $60(35.50)$ & & $55(32.54)$ & $114(67.46)$ & \\
\hline Medullary carcinoma & 27 & $15(55.56)$ & $12(44.44)$ & & $13(48.15)$ & $14(51.85)$ & \\
\hline Clinical stage & & & & 0.249 & & & 0.242 \\
\hline I-II & 141 & $93(65.96)$ & $48(34.04)$ & & $45(31.91)$ & $96(68.09)$ & \\
\hline II-IV & 55 & $31(56.36)$ & $24(43.64)$ & & $23(41.82)$ & $32(58.18)$ & \\
\hline Tumor differentiation & & & & $0.006^{\mathrm{a}}$ & & & $0.023^{\mathrm{a}}$ \\
\hline $\mathrm{T} 1-\mathrm{T} 2$ & 136 & $95(69.85)$ & $41(30.15)$ & & $40(29.41)$ & $96(70.59)$ & \\
\hline T3-T4 & 60 & $29(48.33)$ & $31(51.67)$ & & $28(46.67)$ & $32(53.33)$ & \\
\hline Lymph node metastasis & & & & $0.017^{\mathrm{a}}$ & & & $0.042^{\mathrm{a}}$ \\
\hline N0-N1 & 155 & $105(67.74)$ & $50(32.26)$ & & $48(30.97)$ & $107(69.03)$ & \\
\hline N2-N3 & 41 & $19(46.34)$ & $22(53.66)$ & & $20(48.78)$ & $21(51.22)$ & \\
\hline Distant metastasis & & & & a & & & $0.016^{\mathrm{a}}$ \\
\hline M0 & 174 & $116(66.67)$ & $58(33.33)$ & & $55(31.61)$ & $119(68.39)$ & \\
\hline M1 & 22 & $8(36.36)$ & $14(63.64)$ & & $13(59.09)$ & $9(40.91)$ & \\
\hline
\end{tabular}

${ }^{\text {a }}<0.05$ was considered to indicate statistical significance. BCSC-1, breast cancer suppressor candidate-1; MMP, matrix metalloproteinase.

mRNA and protein expression levels of BCSC-1 and MMP-14 in breast cancer. The mRNA and protein expression levels of BCSC-1 and MMP-14 in the breast cancer tissues and adjacent normal tissues were detected using RT-qPCR and western blot analysis. RT-qPCR revealed low expression of BCSC-1 and high expression of MMP-14 in breast cancer tissues compared with normal tissues; these findings were recapitulated at the protein level using a western blot analysis, and were consistent with those of the immunohistochemical staining. This suggests that BCSC-1 and MMP-14 may be involved in the pathogenesis of breast cancer (Fig. 5).

Correlation analysis of BCSC-1 and MMP-14 expression. Among the 124 cases with low expression of BCSC-1, 27 cases had low expression of MMP-14 and 97 cases had high expression of MMP-14. Among the 72 cases with high expression of BCSC-1, 41 cases had low expression of MMP-14 and
31 cases had high expression of MMP-14. Spearman's rank correlation analysis indicated that there was a negative correlation between BCSC-1 and MMP-14 expression ( $r=-0.356$, $\mathrm{P}<0.01)$ (Table III).

\section{Discussion}

BCSC-1 is a newly discovered cancer-suppressor gene. Martin et al (4) first reported that 33 of 41 tumor cell lines exhibited low expression of the BCSC-1 gene based on northern blot analysis. Meanwhile, the tumorigenicity of human lung cancer H460 cell xenografts in nude mice was significantly decreased after transfection with the BCSC-1 gene. We also found that the tumorigenicity and metastatic capability of the human nasopharyngeal carcinoma cell line CNE-2L2 were decreased significantly with ectopic expression of BCSC-1 gene, while the expression levels 
of E-cadherin, alpha-catenin and p53 were increased and cell-cycle arrest was induced $(4,5)$. The malignancy and proliferative capability of human lung cancer NCI-H446 cells were also inhibited by ectopic expression of the BCSC-1 gene; this inhibitory effect was related to cell-cycle arrest and increased expression of the adhesion molecule CD44. We also found that the migratory and invasive abilities of the human breast cancer cell lines MCF-7 and MDA-MB-231 were reduced significantly by transfection with the BCSC-1 gene and that the expression level of ICAM-1 in the two cell lines was significantly altered, suggesting that BCSC-1 may play an important role in the expression of ICAM-1 (13). However, little has been established regarding BCSC-1 in breast cancer patients until now.

MMP-14 (also known as MT1-MMP) is a membrane-type MMP that contains a membrane structural domain and is fixed on the membrane surface. MMP-14 can not only directly degrade extracellular matrix (ECM) components, such as collagen or fiber-binding proteins, but also can activate other MMP members, such as MMP-2 and MMP-9. MMPs participate in many pathophysiological processes, such as fibrous tissue expansion, tumorigenesis or inflammation $(14,15)$. In addition, increased MMP-14 expression has been observed in the human stomach, lung and neuroblastoma tumor cells and has been correlated with poor patient prognosis (16-18). A meta-analysis of 1,918 cancer patients in 11 studies indicated that MT1-MMP is a prognosticator for poor cancer survival; MMP-14 expression was significantly associated with poor overall survival outcome in patients with lung cancer, gastric cancer or glioma (19). In recent years, studies have confirmed that MMP-14 participates in the formation of invadopodia, which have been regarded as key structures that regulate the metastatic potential of many tumor types and the epithelial-mesenchymal transition process. Inhibiting the activity of MMP-14 can significantly inhibit the activity of invadopodia (20-22). The inhibition of MMP-14 activity by NEDD9-depletion-mediated TIMP2 overexpression can down-regulate the invasive activity of MCF-7 and BT-549 in vitro (23). Ampuja et al confirmed that MMP-14 inhibition can down-regulate the invasive activity of MDA-MB-231 and MDA-MB-361 breast cancer cells in a $3 \mathrm{D}$ environment (24). Blocking the activity of MMP-14 with an anti-MMP-14 inhibitory antibody (DX-2400) can inhibit the tumorigenic ability of the murine breast carcinoma cell lines 4T1 and E0771 (25). Furthermore, the inhibition of MMP-14 by miR-886-5p can downregulate the invasiveness of MCF-7 cells in vitro (26). These experiments indicated that MMP-14 may be a potential therapeutic target for breast cancer. Although the correlations between MMP-14 and clinicopathological features have been investigated in various human carcinomas, little is known about MMP-14 in breast cancer patients. Perhaps due to the lack of samples, reports regarding the relationship between MMP-14 and the clinical characteristics of the patients have been scarce. In the present study, we initially identified the expression of BCSC-1 and MMP-14 in breast cancer using tissue microarrays. The immunohistochemical staining revealed that BCSC-1 was expressed at a low level while MMP-14 was expressed at a high level in breast cancer tissues compared with normal breast tissues, suggesting that BCSC-1 and MMP-14 may be involved in the pathogenesis of breast cancer. Subsequently, 127 cases of
Table III. Correlation between the expression of BCSC-1 and MMP-14.

\begin{tabular}{lrrrrrr}
\hline & \multicolumn{4}{c}{ MMP-14 } & & \\
\cline { 3 - 4 } BCSC-1 & No. & Low & High & r & P-value \\
\hline Low & 124 & 27 & 97 & -0.356 & $<0.01^{\text {a }}$ \\
High & 72 & 41 & 31 & & \\
\hline
\end{tabular}

${ }^{a} \mathrm{P}<0.05$ was considered to indicate statistical significance. BCSC-1, breast cancer suppressor candidate-1; MMP, matrix metalloproteinase.
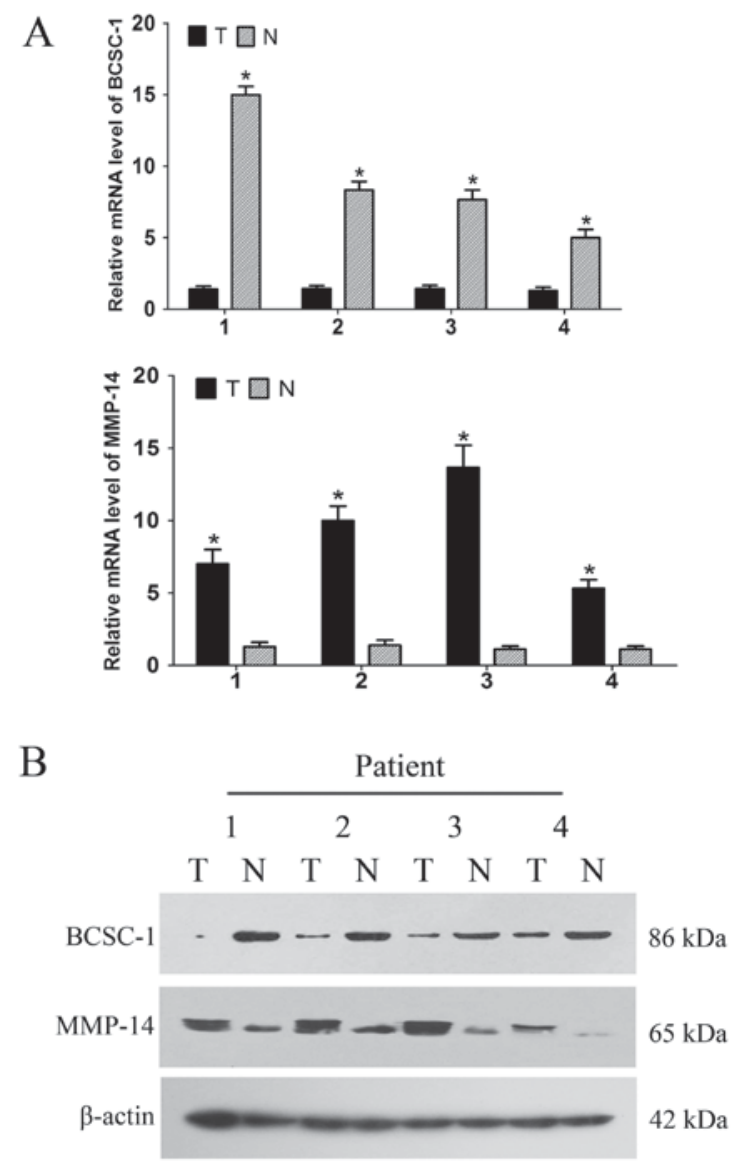

Figure 5. Expression of BCSC-1 and MMP-14 in human breast cancer tissues (T) compared with paired adjacent normal breast tissues (N). (A) mRNA expression of BCSC-1 and MMP-14 in breast cancer tissues and paired adjacent breast tissue samples according to RT-qPCR. (B) Protein expression levels of BCSC-1 and MMP-14 in breast cancer tissues and paired adjacent normal breast tissues according to western blot analysis. ${ }^{*} \mathrm{P}<0.05$. BCSC-1, breast cancer suppressor candidate-1; MMP, matrix metalloproteinase; RT-qPCR, reverse transcription-quantitative PCR.

breast cancer were collected for further confirmation, and the immunohistochemical staining of these tissues was consistent with that of the tissue microarrays, suggesting that BCSC-1 and MMP-14 are involved in the pathogenesis of breast cancer. The results of RT-qPCR and western blot analysis also confirmed the immunohistochemistry results. Additionally, the results indicated that BCSC-1 and MMP-14 expression statuses are closely related to tumor cellular differentiation, lymph node 
metastasis and distant metastasis $(\mathrm{P}<0.05)$; however, they were not significantly associated with patient age, histological type or clinical stage $(\mathrm{P}>0.05)$. These findings indicate that BCSC-1 and MMP-14 may participate in breast cancer metastasis. A correlational analysis between BCSC-1 and MMP-14 was also conducted in the present study, revealing a negative correlation between the two proteins $(\mathrm{P}<0.05)$.

In summary, our study suggested that BCSC-1 is expressed at a low level and MMP-14 is highly expressed in breast cancer tissues compared with normal breast tissues, and that these correlate with tumor cellular differentiation, lymph node metastasis and distant metastasis. Therefore, these proteins may play an important role in breast cancer progression and act as predictive biomarkers.

\section{Acknowledgements}

The present study was supported by grants from the National Natural Science Foundation of China (81373185); the Natural Science Foundation of Shandong, China (ZR2009CM019, ZR2014HL058); Shandong Province Health Department (2013WS0287, 2014WS0462); Student Innovation Program of Weifang Medical University (KX2016020).

\section{References}

1. Fan L, Strasser-Weippl K, Li JJ, St Louis J, Finkelstein DM, Yu KD, Chen WQ, Shao ZM and Goss PE: Breast cancer in China. Lancet Oncol 15: e279-e289, 2014.

2. Hong $\mathrm{W}$ and Dong E: The past, present and future of breast cancer research in China. Cancer Lett 351: 1-5, 2014.

3. Chen W, Zheng R, Baade PD, Zhang S, Zeng H, Bray F, Jemal A, Yu XQ and He J: Cancer statistics in China, 2015. CA Cancer J Clin 66: 115-132, 2016.

4. Martin ES, Cesari R, Pentimalli F, Yoder K, Fishel R, Himelstein AL, Martin SE, Godwin AK, Negrini $M$ and Croce CM: The BCSC-1 locus at chromosome 11q23-q24 is a candidate tumor suppressor gene. Proc Natl Acad Sci USA 100: 11517-11522, 2003.

5. Zhou YQ, Chen SL, Ju JY, Shen L, Liu Y, Zhen S, Lv N, He ZG and Zhu LP: Tumor suppressor function of BCSC-1 in nasopharyngeal carcinoma. Cancer Sci 100: 1817-1822, 2009.

6. Mazumder Indra D, Mitra S, Singh RK, Dutta S, Roy A, Mondal RK, Basu PS, Roychoudhury S and Panda CK: Inactivation of CHEK1 and EI24 is associated with the development of invasive cervical carcinoma: Clinical and prognostic implications. Int J Cancer 129: 1859-1871, 2011.

7. Anghel SI, Correa-Rocha R, Budinska E, Boligan KF, Abraham S, Colombetti S, Fontao L, Mariotti A, Rimoldi D, Ghanem GE, et al: Breast cancer suppressor candidate-1 (BCSC-1) is a melanoma tumor suppressor that down regulates MITF. Pigment Cell Melanoma Res 25: 482-487, 2012.

8. Zhao CL, Yu WJ, Gao ZQ, Li WT, Gao W, Yang WW, Feng WG and Ju JY: Association of BCSC-1 with human esophageal squamous cell carcinoma. Neoplasma 62: 765-769, 2015.

9. Sugiyama N, Gucciardo E, Tatti O, Varjosalo M, Hyytiäinen M, Gstaiger M and Lehti K: EphA2 cleavage by MT1-MMP triggers single cancer cell invasion via homotypic cell repulsion. J Cell Biol 201: 467-484, 2013.

10. von Nandelstadh P, Gucciardo E, Lohi J, Li R, Sugiyama N, Carpen $\mathrm{O}$ and Lehti $\mathrm{K}$ : Actin-associated protein palladin promotes tumor cell invasion by linking extracellular matrix degradation to cell cytoskeleton. Mol Biol Cell 25: 2556-2570, 2014.
11. Xue M, Fang Y, Sun G, Zhuo W, Zhong J, Qian C, Wang L, Wang L, Si J and Chen S: IGFBP3, a transcriptional target of homeobox D10, is correlated with the prognosis of gastric cancer. PLoS One 8: e81423, 2013.

12. Ulasov I, Yi R, Guo D, Sarvaiya P and Cobbs C: The emerging role of MMP14 in brain tumorigenesis and future therapeutics. Biochim Biophys Acta 1846: 113-120, 2014.

13. Di D, Chen L, Wang L, Sun P, Liu Y, Xu Z and Ju J: Downregulation of human intercellular adhesion molecule-1 attenuates the metastatic ability in human breast cancer cell lines. Oncol Rep 35: 1541-1548, 2016.

14. Albrechtsen R, Kveiborg M, Stautz D, Vikeså J, Noer JB, Kotzsh A, Nielsen FC, Wewer UM and Fröhlich C: ADAM12 redistributes and activates MMP-14, resulting in gelatin degradation, reduced apoptosis and increased tumor growth. J Cell Sci 126: 4707-4720, 2013.

15. Taylor SH, Yeung CY, Kalson NS, Lu Y, Zigrino P, Starborg T, Warwood S, Holmes DF, Canty-Laird EG, Mauch C and Kadler KE: Matrix metalloproteinase 14 is required for fibrous tissue expansion. Elife 4: e09345, 2015.

16. Dong Y, Chen G, Gao M and Tian X: Increased expression of MMP14 correlates with the poor prognosis of Chinese patients with gastric cancer. Gene 563: 29-34, 2015.

17. Wang YZ, Wu KP, Wu AB, Yang ZC, Li JM, Mo YL, Xu M, Wu B and Yang ZX: MMP-14 overexpression correlates with poor prognosis in non-small cell lung cancer. Tumour Biol 35: 9815-9821, 2014

18. Nyalendo C, Sartelet H, Barrette S, Ohta S, Gingras D and Béliveau R: Identification of membrane-type 1 matrix metalloproteinase tyrosine phosphorylation in association with neuroblastoma progression. BMC Cancer 9: 422, 2009.

19. Wu KP, Li Q, Lin FX, Li J, Wu LM, Li W and Yang QZ: MT1-MMP is not a good prognosticator of cancer survival: Evidence from 11 studies. Tumour Biol 35: 12489-12495, 2014.

20. Jacob A and Prekeris R: The regulation of MMP targeting to invadopodia during cancer metastasis. Front Cell Dev Biol 3: 4, 2015.

21. Williams KC, McNeilly RE and Coppolino MG: SNAP23, Syntaxin4, and vesicle-associated membrane protein 7 (VAMP7) mediate trafficking of membrane type 1-matrix metalloproteinase (MT1-MMP) during invadopodium formation and tumor cell invasion. Mol Biol Cell 25: 2061-2070, 2014.

22. Miyazawa Y, Uekita T, Ito Y, Seiki M, Yamaguchi H and Sakai R: CDCP1 regulates the function of MT1-MMP and invadopodia-mediated invasion of cancer cells. Mol Cancer Res 11: 628-637, 2013.

23. McLaughlin SL, Ice RJ, Rajulapati A, Kozyulina PY, Livengood RH, Kozyreva VK, Loskutov YV, Culp MV, Weed SA, Ivanov AV and Pugacheva EN: NEDD9 depletion leads to MMP14 inactivation by TIMP 2 and prevents invasion and metastasis. Mol Cancer Res 12: 69-81, 2014.

24. Ampuja M, Jokimäki R, Juuti-Uusitalo K, Rodriguez-Martinez A, Alarmo EL and Kallioniemi A: BMP4 inhibits the proliferation of breast cancer cells and induces an MMP-dependent migratory phenotype in MDA-MB-231 cells in 3D environment. BMC Cancer 13: 429, 2013.

25. Ager EI, Kozin SV, Kirkpatrick ND, Seano G, Kodack DP, Askoxylakis V, Huang Y, Goel S, Snuderl M, Muzikansky A, et al: Blockade of MMP14 activity in murine breast carcinomas: Implications for macrophages, vessels, and radiotherapy. J Natl Cancer Inst 107: pii: djv017, 2015.

26. Zhang LL, Wu J, Liu Q, Zhang Y, Sun ZL and Jing H: MiR-886-5p inhibition inhibits growth and induces apoptosis of MCF7 cells. Asian Pac J Cancer Prev 15: 1511-1515, 2014.

This work is licensed under a Creative Commons Attribution-NonCommercial-NoDerivatives 4.0 International (CC BY-NC-ND 4.0) License. 